\title{
Crisis in leadership vs waste management
}

\author{
Antonis A. Zorpas ${ }^{1}$. Jose Navarro-Pedreño ${ }^{2}$. Mejdi Jeguirim ${ }^{3}$ - Giorgos Dimitriou ${ }^{4}$ - María Belén Almendro Candel ${ }^{2}$. \\ Christos Argirusis $^{5} \cdot$ Ioannis Vardopoulos $^{1} \cdot$ Pantelitsa Loizia $^{1} \cdot$ Georgia Chatziparaskeva $^{1} \cdot$ Iliana Papamichael $^{1}$
}

Published online: 4 December 2021

(c) Springer Nature Switzerland AG 2021

Recent studies have found that the world is now producing over 2 billion tons of solid waste each year, with this number set to rise in the coming decades. Given the UN's Sustainable Development Goals (SDGs), which aim to facilitate a peaceful and prosperous world, we need to consider how materials science research into recycling processes and waste management aimed at combating the global waste crisis has become the biggest mistake of scientists around the world. We are all running behind fundamental research activities, ignoring thoughtful application solutions, and assuming — to quote Nelson Mandela - that other people (in particular politicians) think the way we think.

Several areas around the world (e.g., the Mediterranean region and Central Europe) have dispersed, unsustainable approaches to waste management. In areas in which waste is separated before collection, most of the organic fraction of the municipal solid waste generated by millions of residents (particularly in huge metropolitan areas) is still discarded in landfills. Such an approach is the least sustainable one, as it contradicts the waste hierarchy declared in the Waste

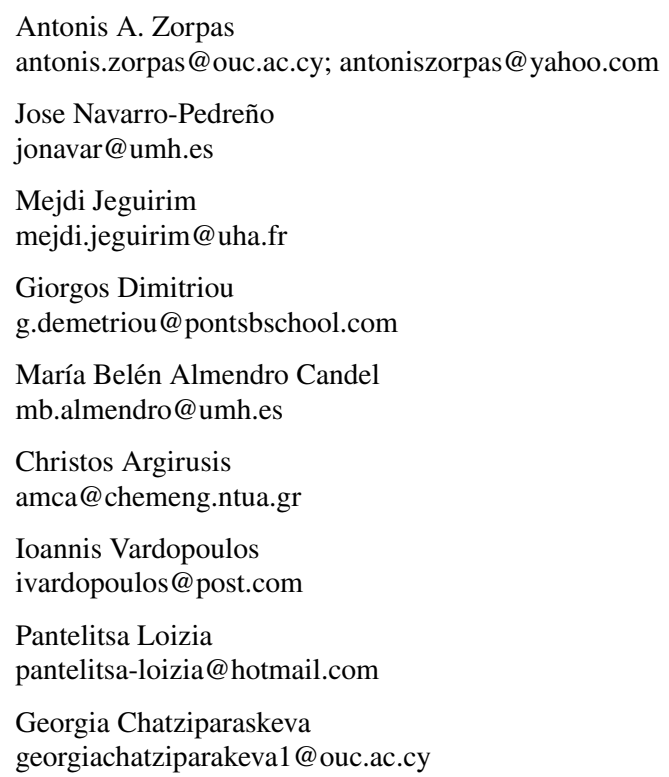

Framework Directive (WFD), the New European Green Deal of December 2019, and the New European Circular Economy Package of April 2018. Sometimes, waste is disposed of directly or after a mechanical biological treatment (MBT) of the unsorted waste. Typically, an MBT has high operating costs and huge entry fees, which sometimes local authorities cannot afford, while its consumption of energy and emissions of $\mathrm{CO}_{2}$ are huge. The high operating costs of MBTs, the low quality of the recyclable materials that they produce, and the poor quality of RDF/SRF (refuse-derived fuel/solid recovered fuel) and compost all prevent local communities from constructing new waste treatment plants, so new initiatives must be proposed. At a political level, the emphasis is more on the achievement of consensus rather than on the creation of a sustainable integrated waste management approach.

Even though waste will continue to increase, and although several attempts are being made to reduce waste at many levels, there is a total absence of a detailed holistic approach to solve the waste management crisis at a political level. In

Iliana Papamichael

iliana.papamichael@gmail.com

Lab of Chemical Engineering and Engineering

Sustainability, Faculty of Pure and Applied Sciences, Open University of Cyprus, 33 Giannou Kranidioti Avenue, 2252, Latisa, Nicosia, Cyprus

2 Department of Agrochemistry and Environment, University Miguel Hernandez of Elche, Alicante, Spain

3 Institut de Science des Matériaux de Mulhouse, 3 bis rue Alfred Werner, 68093 Mulhouse, France

4 Circular Economy Research Center (CERC), Ecole des Ponts Business School, Paris, France

5 School of Chemical Engineering, National Technical University of Athens, 9 Heroon Polytechneiou St., Zografou Campus, 15780 Athens, Greece 
fact, since the Treaty of Rome back in 1957, there has been no joint statement from leaders that they are taking action to protect the environment. For more than 60 years, there has not been any specific initiative at the European level. During the First Environmental Action Program (1973-1977), the prevention plan was described, along with the general directives and legislation, without mentioning specific targets (taking into account existing knowhow and technologies). Several treaties, such as Maastricht, Amsterdam (1999), Nice (2003), and Lisbon (2000 and 2009), did not consider any specific pronouncements from politicians, and almost all of the proposed environmental goals were not achieved (even though those goals were also too limited). The Europe 2020 strategy, which followed the Lisbon 2010 strategy and aims for smart, sustainable, and inclusive growth, was not accomplished. Among the targets of that strategy, the goal to reduce greenhouse gas emissions by at least $20 \%$ compared to 1990 levels (the well-known energy efficiency 20-20-20 target) was not achieved. The main reason that so many targets have not been achieved is how politicians react and get involved with the environmental performance. It is well known that the environment in its general sense as well as waste management and strategies are not considered priorities in any political agenda, and furthermore do not attract the interest of the media industry. To be honest, we do not need other directives or national legislation to boost environmental protection (more than 1200 documents have been released by the EU since 1992) — we just need to apply them by stepping up international action. A serious management crisis was reported in the years following the refusal of the USA to sign the Paris Agreement in 2016. (This agreement sets out a global action plan to put the world on track to avoid dangerous climate change by limiting global warming to well below $2{ }^{\circ} \mathrm{C}$.) The circular economy is gaining increasing attention in Europe and around the world as a solution to the waste crisis, as it is a strategy that maximizes resource efficiency and minimizes waste production in the framework of sustainable development. At the end of 2019, the European Commission proposed the new European Green Deal Strategy. This strategy resets the Commission's commitment to tackling climate and environmentrelated challenges (this generation's defining task) and aims to achieve climate neutrality by 2050 . However, to achieve this goal, politicians must make a lot of effort and accept a new mindset regarding strategy development.

The world's waste is reaching crisis levels. As more and more trash is formed every day, addressing the question of how to deal with this waste is going to become a crucial priority for countries around the globe. Many reports have mentioned that India and China, who are home to $36 \%$ of the global population, account for almost $27 \%$ of the world's waste. At a global level, waste will continue to increase. Annually, $773 \mathrm{~kg}$ is produced by each US citizen, meaning that $12 \%$ of all the waste produced annually originates from the USA. It is awful to think that each US resident generates three times more waste than each resident of China, and up to seven times more waste than each Ethiopian. The quantity of waste generated in Vietnam increases daily and is gradually exceeding the capacity of the Vietnamese government to handle it. At the same time, the average European citizen produces close to $500 \mathrm{~kg}$ annually; citizens of Denmark produce the most per person (more than $800 \mathrm{~kg}$ annually), followed by citizens of Luxemburg and Norway (almost $700 \mathrm{~kg}$ per year). The Mediterranean European countries of Cyprus, Greece, Italy, and Spain produced 630, 520, 500, and $480 \mathrm{~kg}$ per person in 2019, respectively.

According to many reports, such as those from The Economist, World Bank, the International Solid Waste Association, and Eurostat, waste (as defined in a general sense) will continue to increase (Fig. 1). It is estimated that 2.01 billion tons of solid waste were produced in 2016, and the World Bank predicts that this will rise to 3.4 billion tons by 2050 , and to at least 4 billion tons by the end of 2100 . The more urbanized the country, the more trash and waste it produces. In still-urbanizing cities, many of which are in Asia and Africa, the quantity of waste produced is expected to double as a result of population growth, urbanization, and increased consumption. The leading waste generators worldwide are considered to be the USA, Brazil, India, China, Germany, and Japan. Waste forecasts indicate that the USA generates more than 600,000 metric tons per day, China generates more than 500,000 metric tons per day, while Brazil, Japan, and Germany generate more than 130,000 metric tons per day. Moreover, waste prediction statistics point to the presence of infinity illegal dumpsites globally, which may serve nearly 4 billion citizens (half of the planet's population) and receive almost $40 \%$ of the waste generated globally. Additionally, food waste, which is mostly a social rather than an environmental issue, contributes to the production of almost 4 billion tons of $\mathrm{CO}_{2}$-equivalent emissions, as almost one-third of all food produced is wasted. Furthermore, a vital and unsolved issue behind any fundamental research is microplastic and plastic pollution (which is currently under investigation), as such pollution will continue to increase due to the fact that consumers will never stop using plastic. Even though plastic is a remarkable material that can be turned into varied forms, it is estimated that up to 8 billion metric tons of plastic pollution have been generated in the last 60 years. According to beach litter counts, almost 85\% of the marine litter in the EU is plastic, with single-use plastic items representing 50\% and fishing-related items representing $27 \%$ of the total. Moreover, it is extremely difficult to retrieve the plastic waste already in oceans, although we can apply policies and strategies to retrieve them through activities such as beach cleaning around the world or "plastic fishing." A more serious issue for waste generation globally 


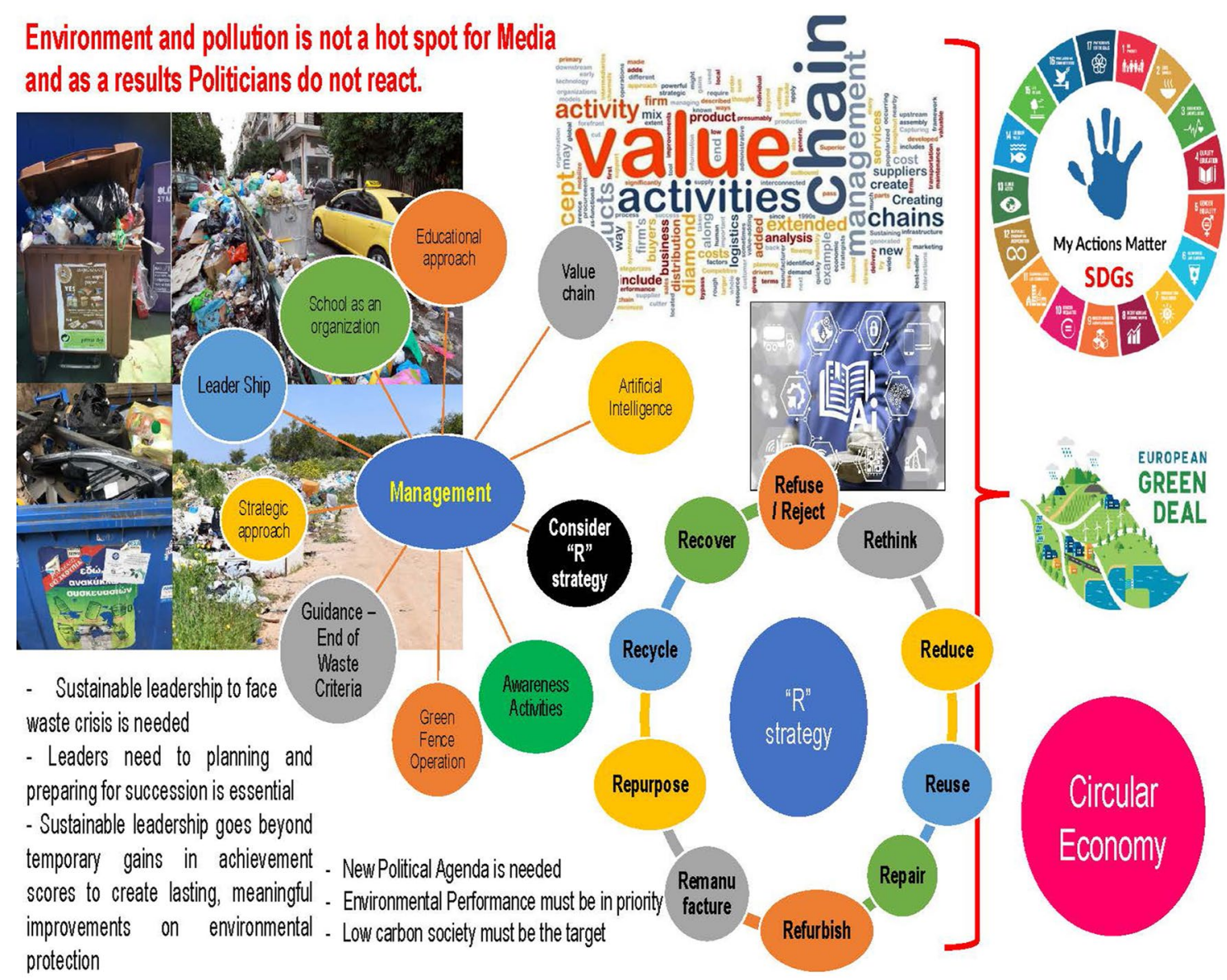

Fig. 1 Graphical Abstract

is the fact that politicians and policy makers have not linked poverty (SDG 1) with pollution (or have avoided doing so). There is a strong link between poverty and plastics. If we consider the case of single-use plastic, this remarkable material provides a way for poor communities to access a number of products such as soap, shampoo, and toothpaste. These products help countries such as India to increase their GDP, to reduce poverty, and to increase quality of life by enabling the development of schools, hospitals, infrastructure, etc. However, globally, a trillion single-use plastic bags are used annually ( 2 million per minute), and the amount of energy required to produce 12 plastic shopping bags could drive a car for $1.5 \mathrm{~km}$. Consequently, there are obviously differences in the luxury of choice between different sections of society and socioeconomic groups. More thought ought to be given to product design when choosing between a circular and a linear economy. At present, products such as plastics are designed without giving any thought to what happens to them at the end of their life cycle. Industries and organizations of all sizes have to start thinking about designing products for reuse, recycling, and remanufacture. Dyeing a plastic bottle purple may be a great marketing strategy, but such a bottle is difficult to recycle whereas clear and white bottles are not. The motivation from policy makers directed to those enterprises to redesign their products or services, is of outmost importance, yet not been provided, thus creating a huge research opportunity in the scientific area of environmental policy. Presently, a quarter of all plastic waste is not collected, leaving individuals to dispose of it themselves. By $2040,30 \%$ of all plastic waste created will be uncollectedequal to 143 million tons per year.

Waste that is not collected also causes important issues: it clogs up rivers and drains, it gets rejected in the ocean, or, if left in urban zones, it can lead to disease, infections, and illness. Moreover, waste collection is considered to be among the most fundamental approaches to preventing and reducing pollution. Globally, there are around 11 million waste pickers, and almost all of them are looking for material that they can sell on for recycling. It is believed that those pickers collect about $58 \%$ of all the plastic material recycled globally (much more than all the formal authorities collect put together). Furthermore, uncollected waste can reduce land market values, decrease quality of life, and destroy local tourist economies. Several measures must be put in place to 
deal with the reality of waste generation. Policy makers and politicians must realize that they must invest in proper waste management, as this is a vital issue.

The lack of an educational program and awareness activities, the absence of waste infrastructure and a waste strategy, along with micromanagement at a local political level and high waste management costs result in wrong political decisions regarding waste strategy development. In addition, as political parties place environmental protection at the bottom of their political agendas, and because politicians and political parties are not convinced that environmental production must be a priority (as, for many reasons, they have never based their election strategies on environmental issues), a new approach to solving the waste crisis by linking green entrepreneurship with the environment must be applied.

An absence of leadership in education is also considered to be leading to inappropriate waste management practices. An appropriate educational program has a direct affect on social attitudes and social behaviors. It may affect any waste prevention, reuse, remanufacturing, or refurbishment scheme, and-in particular-any recycling or materials recovery program. If citizens do not behave appropriately in a recycling program, such as properly sorting their waste at source, this may affect the entire Green Fence Operation (the global market for recycling materials). Each day across the USA and EU, about 4000 shipping containers are packed full of recyclables and trucked to seaports, where they are loaded onto cargo boats and forwarded to China. The recyclables in those containers include rubber, plastics, metals, paper, cardboard, and textiles, which are used as raw materials by Chinese producers, thus contributing to the circular economy strategy. However, according to the MRF indicator (which specifies how "clean" or "dirty" the waste is), the quality of the recyclables entering China started to decrease, as most of the recyclable materials (such as plastics, scrap metal, and fibers) contained too much food, trash, and other contaminants. The Chinese government, looking to protect its homeland manufacturers and mindful of the environmental impact of the dirty waste, decided it would take action to improve the quality of the raw materials it accepts through enhanced inspection of the recyclables exported to China and by introducing the specification that the MRF (material recovery facility) indicator must be $\leq 1 \%$. This Chinese policy decision created a waste crisis that has turned into a political crisis, as it has meant that, globally, millions of tons of recyclable materials have required a new solution. Many companies, especially in the USA and Europe, have had to send recycling to landfills, since there was nowhere else to place it (a painful reversal after decades of growth in recycling programs). Furthermore, with China out of the market, the cost of managing the recycling program has tripled.
Accordingly, ended in a crisis of leadership, as leaders could not find any solution. A sustainable education program that engages primary and secondary schools, an appropriate awareness campaign that involves citizens and stakeholders, and a smart gamification approach to motivate citizens to react to the global debates, thus increasing their participation in any environmental program (waste prevention or reuse, material exchange, nonproduction of waste, recycling, etc.), are essential.

Considering the end-of-waste criteria (EWC) defined in the obligatory Article 6 of the Waste Framework Directive (WFD), society could develop a zero-waste world, as many other items can be produced from several products that have reached the ends of their lives. The target of the EWC is to produce an effective approach with high-quality recyclable materials that encourages product standardization, quality and safety assurance, and improved harmonization and legal certainty in the recyclable material markets. Furthermore, the EWC aim to design, establish, and promote a strategic approach to improving generation 4.0 environmental technologies. The EWC refer to the concept where new life is given to any kind of waste. Imagine new ecodesigns of products (such as kitchens, chairs, sofas, tables, clothes, and construction materials) produced from waste. Mostly, it is not about "label names." It is about learning, but mostly it is about developing a new mindset for citizens and for companies. A methodology to develop EWC was proposed by JRC (2008) and Zorpas (2015), and some modifications were made to it by Antoniou and Zorpas (2019) and Kazamias and Zorpas (2021), but there is still a lot to be done. Additionally, through the WFD, the "polluter pays principle" and the "extended producer responsibility" are included. These incorporate provisions on hazardous waste and waste oils and include two new recycling and recovery targets: (i) 50\% preparing for reuse and recycling of certain waste materials from households and other origins similar to households, and (ii) 70\% preparing for reuse, recycling, and other recovery of construction and demolition waste. Through the WFD, member states should adopt and implement an appropriate waste management strategy that considers waste prevention, reuse, recycling, remanufacture, upcycling, redesign, etc. In general, what must be invested in is the development and establishment of initiatives to boost strategies in the framework of the circular economy and the European Green Deal. Those initiatives may include artificial intelligence (AI), where applicable, and motivational measures (for citizens and stakeholders), and should boost the application of environmental management systems (i.e. ISO 14001, EMAS, Eco-Label, etc.), smart collection systems, advanced waste strategies, key performance indicators, tools to measure the environmental performance in an area, zero waste initiatives, etc. Moreover, an alternative to the circular system must be developed. It is not easy to imagine 
a zero-waste world, but it should at least be attempted. Waste remanufacturing must be prioritized, and policy makers and politicians must invest in this.

To achieve all the new targets set for the circular economy and European Green Deal to solve the waste crisis, politicians must reschedule their political agendas. In this respect, scientists must get out of their laboratories and try to build synergies by interconnecting fundamental research with civil society. We, the authors on the journal's Editorial Board, along with our research institutes (the Laboratory of Chemical Engineering and Engineering Sustainability at the Open University of Cyprus, the Department of Agrochemistry and Environment at Miguel Hernandez University of Elche-Spain, the Institut de Science des Matériaux in Mulhouse-France, the Ecole des Ponts Business School, Circular Economy Research Center-France and the School of Chemical Engineering at National Technical University of Athens-Greece), will use an international conference to offer our knowledge and knowhow, and, moreover, compulsory technical expertise, training, and information-innovation development regarding the development of strategies for waste management considering the operative adoption of a circular economy and the European Green Deal strategy. Additionally, researchers, consultants, practitioners, and policy makers are encouraged to publish their pertinent findings on waste strategies in this journal without any restriction.

\section{References}

Antoniou N, Zorpas AA (2019) Quality protocol development to define end-of-waste criteria for tirepyrolysis oil in the framework of circularl economy strategy. Waste Manag 95:161-170. https://doi. org/10.1016/j.wasman.2019.05.035

Kazamias G, Zorpas AA (2021) Cutting drilling waste from oil \& gas exploitation managementthrough end-of-waste criteria in the framework of circular economy strategy. J Cleaner Prod 322:129098. https://doi.org/10.1016/j.jclepro.2021.129098

JRC (2008) Scientific and technical report; end of waste criteria. Institute for prospective and technological studies, European Commission. http://susproc.jrc.ec.europa.eu/documents/Endofwastecrite riafinal.pdf. Accessed 3 Mar 2021

Zorpas AA (2015) Sustainable waste management through end of waste criteria development. Environ Sci Pollut Res, pp 1-14. https://doi. org/10.1007/s11356-015-5990-5 